\title{
Current Sodium Intakes in the United States and the Modeled Effects of Glutamate Incorporation into Select Savory Products
}

\author{
Taylor C. Wallace ${ }^{1,2}\left(\mathbb{D}\right.$, Alexandra E. Cowan ${ }^{3}$ and Regan L. Bailey ${ }^{3, *(1)}$ \\ 1 Department of Nutrition and Food Studies, George Mason University, Fairfax, VA 22030, USA; \\ taylor.wallace@me.com \\ 2 Think Healthy Group, Inc., Washington, DC 20036, USA \\ 3 Department of Nutrition Science, Purdue University, West Lafayette, IN 47907, USA; acowan9@purdue.edu \\ * Correspondence: reganbailey@purdue.edu; Tel.: +1-765-494-0674
}

Received: 11 September 2019; Accepted: 2 November 2019; Published: 7 November 2019

\begin{abstract}
Most Americans have dietary sodium intakes that far exceed recommendations. Given the association of high sodium with hypertension, strategies to reduce sodium intakes are an important public health target. Glutamates, such as monosodium glutamate, represent a potential strategy to reduce overall intakes while preserving product palatability; therefore, this project aimed to model sodium replacement with glutamates. The National Cancer Institute method was used to estimate current sodium intakes, and intakes resulting from glutamate substitution $(25 \%-45 \%)$ in a limited set of food groups for which substitution is possible. Data sets for individuals aged $\geq 1$ year enrolled in the U.S. National Health and Nutrition Examination Survey 2013-2016 $(n=16,183)$ were used in the analyses. Glutamate substitution in accordance with the U.S. Department of Agriculture's food codes was modeled by conservatively altering estimates of sodium intake reductions derived from the published, peer-reviewed literature. The addition of glutamates to certain food categories has the potential to reduce the population's sodium intake by approximately $3 \%$ overall and by $7 \%-8 \%$ among consumers of $\geq 1$ product category in which glutamates were substituted for sodium chloride. Although using glutamates to substitute the amount of sodium among certain food groups may show modest effects on intakes across the population, it is likely to have a more substantial effect on individuals who consume specific products.
\end{abstract}

Keywords: sodium; glutamate; NHANES; usual intake; chronic disease risk reduction

\section{Introduction}

Dietary sodium reduction is an important goal for the improvement of public health, as reduced sodium intake has been shown to decrease hypertension risk [1]. Hypertension is a valid surrogate endpoint reflective of risks for a myriad of cardiovascular diseases, a leading source of mortality in U.S. adults [2]. Many multifaceted policy and education initiatives aimed at reducing sodium intakes have been ongoing for decades. It has been estimated that a $40 \%$ reduction in the U.S. population's intake of sodium over 10 years may save at least 280,000 lives [3] and drastically reduce the number of disability-adjusted life years (DALYs). Despite ongoing public health education and policy initiatives, the preponderance of the U.S. population exceeds current recommendations for sodium intake [4]. Among hypertensive adults, $86 \%$ exceed $2300 \mathrm{mg}$ dietary sodium/day [5].

Trends in sodium intakes have not changed over the past 10 years (five U.S. National Health and Nutrition Examination Survey (NHANES) cycles) [6]. Those with the lowest household education, non-Hispanic black race/Hispanic origin, and lowest income have seen the largest increase in sodium 
intakes derived from snack foods from 1977-1978 to 2011-2014 [7]. Sodium is primarily consumed as sodium chloride $(\mathrm{NaCl})$ and the majority of intake is derived from sodium added during food processing for the purposes of providing flavor or food safety properties. $\mathrm{NaCl}$ may also be used as a processing aide. More than $70 \%$ of sodium intake in the United States comes from commercially processed and restaurant foods and no single category comprises $>7 \%$ of total intake [8]. With the exception of milk, which naturally contains sodium, the top ten food categories contributing sodium to the diet of U.S. school-aged children are composed of foods in which sodium is added during processing or preparation [9]. Yeast breads contribute the most sodium to the U.S. diet (for individuals aged $\geq 2$ years) [8].

Sodium reduction poses technical challenges given its role in the palatability and safety of food (e.g., preventing bacterial growth and spoilage) [10]. When salt is reduced, palatability and consumer acceptance of a product generally tends to decrease. In 2016, the U.S. Food and Drug Administration (FDA) published draft guidance on voluntary sodium reduction goals for public comment with an aim to reduce U.S. daily intake from $3400 \mathrm{mg}$ to $3000 \mathrm{mg}$ within 2 years (short-term goal) and to $2300 \mathrm{mg}$ within 10 years (long-term goal) [11]. This gradual process set reduction targets for $>150$ food categories.

Currently, no perfectly viable alternative for replacing sodium exists in the contemporary food marketplace, although several innovations do exist among various product categories. For example, glutamate, a nonessential amino acid, has been used to enhance the taste and palatability of food. Indeed, the 2010 Institute of Medicine (now the Institute of Medicine) report, Strategies to Reduce Sodium Intake in the United States, emphasizes that achieving lower intakes of excessive sodium should be a critical focus for all Americans and it is possible to use monosodium glutamate (MSG), the most common glutamate salt and flavor enhancer, to lower the overall sodium level in certain foods while maintaining palatability [10]. MSG contains about $12 \%$ sodium, which is less than one-third of that contained in table salt (39\%) [12]. There is an appropriate amount of MSG that can be used to replace salt while maintaining consumer acceptance in food [12]. Excess MSG does not promote umami taste, and to the contrary, may negatively impact the taste profile of food, most notably at levels $>1 \%$ [13]. Although MSG is the most widely used flavor enhancer in food, other effective glutamate salts, such as calcium di-glutamate, exist but do not provide as pronounced of an effect. A considerable number of studies have demonstrated that various forms of glutamate can help reduce the amount of sodium in specific foods, including soups, prepared dishes, processed meat, and dairy products, by enhancing palatability [14-21]. However, much less is known about how glutamate substitution would affect sodium intakes at the population level across a range of different foods. Therefore, the purpose of this study was to first estimate contemporary sodium intakes of the U.S. population, and then to model MSG substitution in select products-with substantial supportive literature to ensure feasibility-to estimate potential population-level reductions in sodium intakes.

\section{Materials and Methods}

\subsection{Study Population}

The NHANES, conducted by the Centers for Disease Control and Prevention (CDC) National Center for Health Statistics (NCHS), is a nationally representative, continuous, cross-sectional survey of noninstitutionalized, civilian residents of the United States [22]. Since 1999, the NHANES protocol has included an in-person household interview component and a follow-up health examination in the mobile examination center (MEC) for each participant. The NHANES survey protocol was approved by the CDC NCHS Research Ethics Review Board, and written informed consent was obtained for all survey participants or proxies [22]. Data from NHANES 2013-2016 were combined for these analyses. Pregnant and/or lactating women $(n=112)$ were excluded, yielding a combined sample of 16,183 participants who had completed and provided 24-hour dietary intake data. Further analyses evaluating the contributions of select food categories to total sodium intake from the diet were limited to U.S. 
adults ( $\geq 19$ years), excluding those aged $\leq 19$ years $(n=6071)$, yielding a final analytic sample size of 10,112 U.S. adults ( $\geq 19$ years).

\subsection{Demographic Data}

All demographic data used for this analysis, including data on sex and age, were collected from participants using the computer-assisted personal interview system during the household interview. Age was categorized to be consistent with the dietary reference intake (DRI) age groups, defined as $1-3,4-8,9-13,14-18,19-30,31-50,51-70$, and $\geq 71$ years, and was used to compare estimates of sodium intakes. Children and adults were defined as those individuals who were aged 1-18 and $\geq 19$ years, respectively.

\subsection{Dietary Sodium Intake}

NHANES participants were asked to complete two 24-hour dietary recalls for the collection of dietary intake data. The first 24-hour dietary recall was self-reported in the MEC and collected in person by trained NHANES interviewers. The second 24-hour dietary recall interview was completed via telephone approximately 3-10 days after the MEC examination. Both 24-hour recalls were collected by trained interviewers using the U.S. Department of Agriculture's (USDA) validated, automated, multiple-pass method $[23,24]$. Proxy respondents provided dietary intake data for young children and proxy-assisted interviews were utilized for children aged 6-11 years. Questionnaires, data sets, and all related documentation from each NHANES cycle can be found on the NCHS website [25]. The USDA Food and Nutrient Database for Dietary Studies was used to convert foods and beverages (as reported) to their respective sodium intake values [26].

\subsection{Comparison to DRI Values}

The DRIs are a set of nutrition reference values, defined by the National Academies of Sciences, Engineering and Medicine (NASEM) Food and Nutrition Board, that are designed to assess nutrient intakes of healthy people and establish guidelines for risk assessment in the United States and Canada [27]. The DRIs for sodium and potassium were recently updated in 2019, and for the first time, a new category of DRIs based on chronic disease, called the chronic disease risk reduction (CDRR), was established for sodium [1]. Other DRIs established by the NASEM for sodium include the estimated average requirement, recommended dietary allowance, adequate intake, and tolerable upper intake level (UL). DRI values differ for individuals based on age and sex [1]. Sodium was reported as usual intake and the proportion of the population with intakes above the CDRR and UL. Information regarding the recent DRIs for sodium and potassium can be found in the NASEM report, Dietary Reference Intakes for Sodium and Potassium [1].

\subsection{Sodium Intake Modeling}

Glutamates, such as MSG, are flavor enhancers that have been effectively used to reduce sodium in certain food categories, particularly in savory products. A review of the scientific literature demonstrates that glutamates have been utilized to reduce sodium among various mainstream products (Table 1). Assuming that the food supply already contains a significant amount of glutamates and that amounts used among products vary, we made conservative assumptions, in consultation with food scientists, of a $25 \%-45 \%$ reduction in sodium by substitution of sodium chloride with glutamate salts across certain categories of foods using the USDA food codes (Table 2). Consumers of glutamates were those who reported consumption of one or more food categories in which glutamates were substituted for sodium chloride. 
Table 1. Sodium reduction in various food products with the incorporation of glutamates.

\begin{tabular}{llc}
\hline \multicolumn{1}{c}{ Reference } & \multicolumn{1}{c}{ Food } & Sodium Reduction (\%) \\
\hline Ball et al. [14] & & \\
Yamaguchi and Takahashi [15] & Soups & 40 \\
Roininen et al. [16] & Spicy soups & 33 \\
Jinap et al. [17] & Chicken broth & 38 \\
Carter et al. [18] & Sausage & 50 \\
dos Santos et al. [19] & Mozzarella cheese & 54 \\
Rodrigues et al. [28] & Fish burgers & 50 \\
de Quadros et al. [20] & Chips and rice puffs & 51 \\
Buechler [29] & Chicken rice mixed dish & 31 \\
Leong et al. [21] & Mee soto broth & 22 \\
Leong et al. [21] &
\end{tabular}

Table 2. Sodium reduction assumptions due to incorporation of glutamates by USDA food code ${ }^{1}$

\begin{tabular}{|c|c|}
\hline USDA Food Code & Sodium Reduction (\%) \\
\hline \multicolumn{2}{|l|}{1 Milk and Milk Products } \\
\hline \multicolumn{2}{|l|}{14 Cheeses } \\
\hline 140 Cheese, NS as to type & 45 \\
\hline 141 Natural cheeses & 45 \\
\hline 144 Processed cheeses and cheese spreads & 45 \\
\hline 145 Imitation cheeses & 45 \\
\hline 147 Cheese soups & 45 \\
\hline \multicolumn{2}{|l|}{2 Meat, Poultry, Fish, and Mixtures } \\
\hline \multicolumn{2}{|l|}{25 Organ meats, sausages and lunchmeats, and meat spreads } \\
\hline \multicolumn{2}{|l|}{252 Frankfurters, sausages, lunchmeats, and meat spreads } \\
\hline 2521 Frankfurters & 40 \\
\hline 2522 Sausages & 40 \\
\hline 2523 Luncheon meats (loaf) & 40 \\
\hline 2524 Potted meat, spreads & 40 \\
\hline \multicolumn{2}{|c|}{28 Frozen and shelf-stable plate meals, soups, and gravies with meat, poultry, fish base; } \\
\hline \multicolumn{2}{|c|}{ gelatin and gelatin-based drinks } \\
\hline \multicolumn{2}{|c|}{281 Frozen or shelf-stable plate meals with meat, poultry, fish as major ingredient } \\
\hline 2811 Beef frozen or shelf-stable meals & 25 \\
\hline 2812 Pork or ham frozen or shelf-stable meals & 25 \\
\hline 2813 Veal frozen or shelf-stable meals & 25 \\
\hline 2814 Poultry frozen or shelf-stable meals & 25 \\
\hline 2815 Fish, shellfish frozen meals & 25 \\
\hline 2816 Miscellaneous meat frozen or shelf-stable meals & 25 \\
\hline \multicolumn{2}{|l|}{283 Soups, broths, extracts from meat, poultry, fish base } \\
\hline 2831 Beef soups & 30 \\
\hline 2832 Pork soups & 30 \\
\hline 2833 Lamb soups & 30 \\
\hline 2834 Poultry soups & 30 \\
\hline 28345 Poultry cream soups & 30 \\
\hline 2835 Fish, shellfish soups & 30 \\
\hline 2836 Puerto Rican soups & 30 \\
\hline 285 Gravies from meat, poultry, fish base & 30 \\
\hline \multicolumn{2}{|l|}{5 Grain Products } \\
\hline \multicolumn{2}{|l|}{54 Crackers and salty snacks from grain products } \\
\hline 540 Crackers, NS as to type & 40 \\
\hline 543 Nonsweet crackers & 40 \\
\hline 544 Salty snacks from grain products & 40 \\
\hline
\end{tabular}


Table 2. Cont.

\begin{tabular}{lc}
\hline USDA Food Code & Sodium Reduction (\%) \\
\hline 7 Vegetables & \\
71 White potatoes and Puerto Rican starchy vegetables & 30 \\
718 Potato soups & 30 \\
72 Dark-green vegetables & 30 \\
723 Dark-green vegetable soups & 30 \\
73 Deep-yellow vegetables & 30 \\
735 Deep-yellow vegetable soups & 30 \\
74 Tomato and tomato mixtures & \\
746 Tomato soups & 30 \\
75 Other vegetables & \\
756 Vegetable soups & \\
77 Vegetables with meat, poultry fish & \\
775 Puerto Rican stews or soups with starchy vegetables (viandas) & \\
\hline
\end{tabular}

${ }^{1}$ USDA, U.S. Department of Agriculture; NS, not specific.

\subsection{Statistical Analyses}

The National Cancer Institute (NCI) method was used to determine estimates of usual intake of sodium from the diet. Covariates used in the NCI model were as follows: (1) sequence of 24-hour recall (first or second dietary recall); and (2) day of the week the 24-hour recall was collected (weekend/weekday). All statistical analyses were performed using SAS software (version 9.3; SAS Institute Inc., Cary, NC, USA). SAS macros necessary to fit this model and to perform estimation of usual intake distributions, as well as additional details and resources concerning the NCI Method, are available via the NCI website [30]. The fitted model is a two-part model that first uses logistic regression to estimate the probability of intake consumption for each consumer, and then, secondly, uses linear regression to estimate the actual daily amount of intake on a transformed scale, while taking into account within-person variation [30]. Sample weights were used to account for differential nonresponse and noncoverage and to adjust for planned oversampling of some groups, in order to generate a nationally representative sample. Standard errors for all statistics of interest were approximated using Fay's modified, balanced, repeated-replication technique [31,32].

\section{Results}

\subsection{Current Mean Sodium Intakes, Percentages above the CDRR, and Percentages above the UL}

Overall, sodium intakes among the general U.S. population are higher than federal recommendations. On the basis of NHANES 2013-2016 data, Americans (aged $>1$ year) consume approximately $3361 \mathrm{mg}$ sodium/day on average (Table 3). Mean daily sodium intake from foods and beverages among the U.S. population was $2906 \mathrm{mg} /$ day for children (aged 1-18 years) and $3499 \mathrm{mg} /$ day for adults (aged $\geq 19$ years).

Table 3. Estimated and potential means usual sodium intake (in milligrams) from dietary sources and the estimated percentages of mean usual-sodium intakes greater than the CDRR and UL in the U.S. population (aged $\geq 1$ year) by age and sex, NHANES 2013-2016 ${ }^{1,2}$

\begin{tabular}{lccccccc}
\hline \multirow{2}{*}{ Age (Years) } & \multirow{n}{*}{$\boldsymbol{n}$} & \multicolumn{3}{c}{ Current Intake } & \multicolumn{3}{c}{ Potential Intake } \\
\cline { 3 - 7 } & & Mean (SE) & $\begin{array}{c}\%>\text { CDRR } \\
\text { (SE) }\end{array}$ & $\begin{array}{c}\text { \% > UL } \\
\text { (SE) }\end{array}$ & Mean (SE) & $\begin{array}{c}\text { \% >CDRR } \\
\text { (SE) }\end{array}$ & $\begin{array}{c}\text { \% > UL } \\
\text { (SE) }\end{array}$ \\
\hline All $(\geq 1)$ & 16,183 & $3360.7(19.9)$ & $86(0.4)$ & $85(0.5)$ & $3198.7(18.2)$ & $83(0.5)$ & $82(0.5)$ \\
Children (1-18) & 6071 & $2905.8(26.9)$ & $88(0.7)$ & $81(0.9)$ & $2743.0(23.4)$ & $85(0.7)$ & $76(0.9)$ \\
Adults $(\geq 19)$ & 10,112 & $3499.0(23.9)$ & $88(0.6)$ & $88(0.6)$ & $3330.7(21.9)$ & $85(0.6)$ & $85(0.6)$ \\
\hline
\end{tabular}


Table 3. Cont.

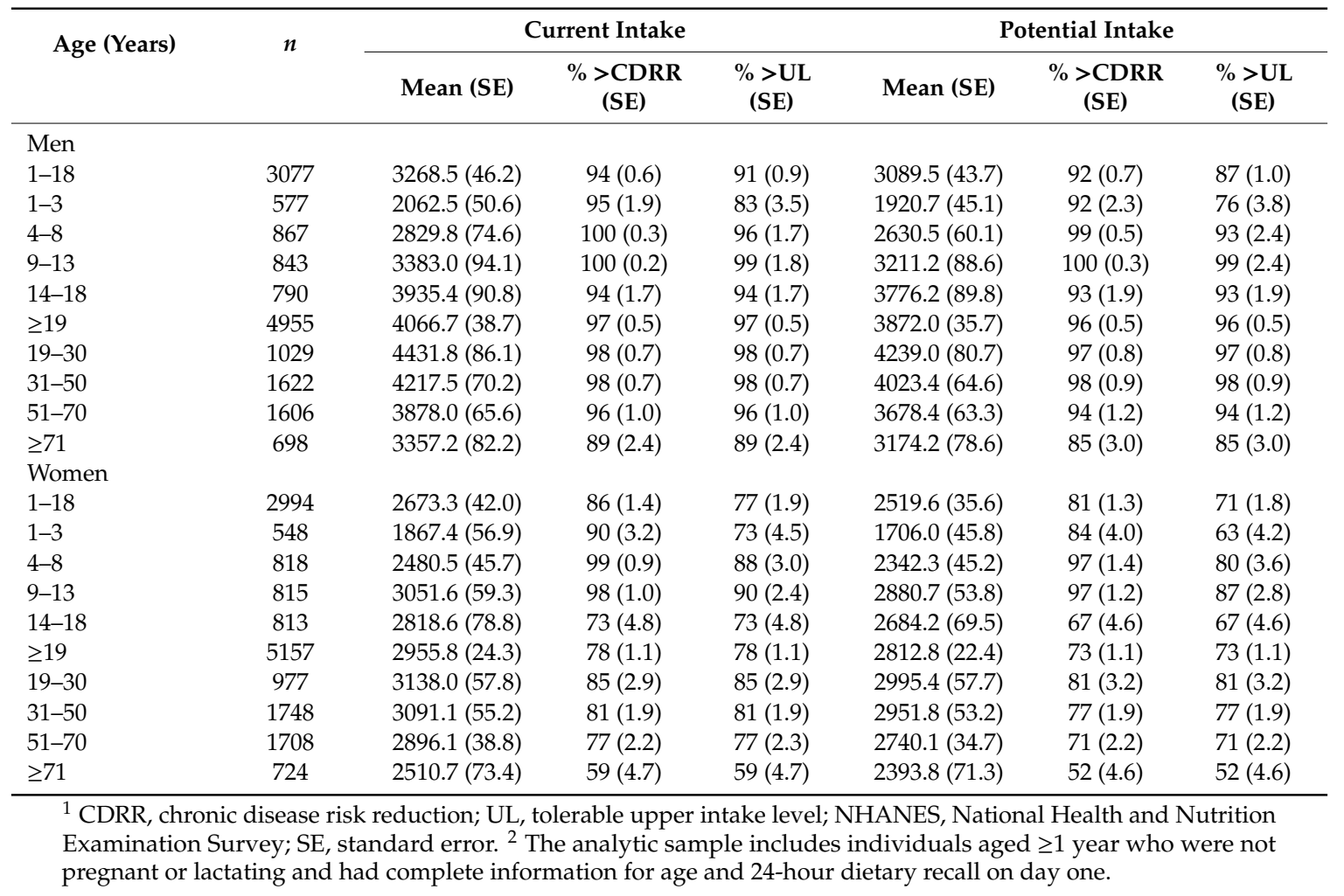

Regardless of age, men had higher sodium intakes than women. Specifically, among adults $(\geq 19$ years), men typically consumed approximately $4067 \mathrm{mg}$ sodium/day, whereas women only consumed approximately $2956 \mathrm{mg}$ sodium/day. Similar themes were apparent among children (1-18 years); boys had higher mean sodium intakes than girls (3268 versus $2673 \mathrm{mg} /$ day, respectively). Therefore, women of all ages were less likely to exceed the CDRR and UL compared to men.

Across age subgroups, sodium intake was highest among men and women aged 19-30 years (4431 versus $3138 \mathrm{mg} /$ day, respectively) and varied across the life course. For men, sodium intake increased with age in the adolescent years (1-18 years), plateaued among early adulthood (19-30 years), and then decreased through the remainder of adulthood ( $\geq 31$ years). However, slightly different patterns were observed among women. Whereas sodium intakes among young girls increased with age until 9-13 years, a slight decrease in intake was observed between the ages of 14-18 years, followed by an increase in intake from 19-30 years, and lastly, a final decrease in intake for the remainder of adulthood ( $\geq 31$ years). Older adults ( $\geq 71$ years) had the lowest sodium intakes of all adult participants among both men and women. Thus, younger adults were more likely to exceed the CDRR and UL for sodium compared to their older adult ( $\geq 71$ years) counterparts. Among children, boys and girls in the $4-8$-year and 9-13-year life stages had the highest prevalence of exceeding the CDRR and UL.

Estimated mean sodium intake and the percent-wise contributions for selected food categories to total sodium intake in the diets of U.S adults ( $\geq 19$ years) and children (1-18 years) are presented in Tables 4 and 5. On a population level, no individual food group contributes large amounts of sodium to the diet; sodium intakes appear to be widespread throughout the food supply. However, the savory food groups represented in Tables 4 and 5 provide much larger proportions of sodium to the diets of those who consumed these products (i.e., "consumers"). For example, meat-based frozen meals provide $0.3 \%$ of the sodium present in the diets of all U.S adults, but as much as one-third (32\%) among consumers. Among children, the top three contributors to total sodium intakes are crackers and salty snacks, cured meats, and select cheeses (Table 5). Although intakes of these select food categories remain high overall, intakes among consumers of these categories are significantly higher than the 
general population of U.S. children (Figure 1). For cured meats in particular, children who consume these products receive $20 \%$ of their usual sodium intake from this source, whereas cured meats account for only $4 \%$ of total sodium intakes among the general population of U.S. children.

Table 4. Estimated mean sodium intake (in milligrams) and percentage-wise contributions from selected food groups in the diets of U.S. adults (aged $\geq 19$ years) by age and sex, NHANES 2013-2016 1,2,3.

\begin{tabular}{|c|c|c|c|c|c|c|}
\hline \multirow{2}{*}{ Figure } & \multicolumn{2}{|c|}{ All Adults } & \multicolumn{2}{|c|}{ Men } & \multicolumn{2}{|c|}{ Women } \\
\hline & Consumers & All Adults & Consumers & All Men & Consumers & All Women \\
\hline \multicolumn{7}{|l|}{ Select cheeses } \\
\hline$n$ & 3115 & 10,112 & 1515 & 4955 & 1600 & 5157 \\
\hline Mean (SE) & $303(8.2)$ & $109(4.2)$ & $348(12.6)$ & $127(6.0)$ & $258(8.6)$ & $92(4.4)$ \\
\hline$\%$ contribution (SE) & $8(0.2)$ & $3(0.1)$ & $8(0.3)$ & $3(0.1)$ & $9(0.3)$ & $3(0.1)$ \\
\hline \multicolumn{7}{|l|}{ Cured meats } \\
\hline$n$ & 1886 & 10,112 & 1049 & 4955 & 837 & 5157 \\
\hline Mean (SE) & $825(21.0)$ & $159(6.1)$ & $908(33.8)$ & $202(10.1)$ & 715 (23.6) & $117(7.1)$ \\
\hline$\%$ contribution (SE) & $21(0.4)$ & $4(0.2)$ & $20(0.5)$ & $5(0.2)$ & $22(0.7)$ & $4(0.2)$ \\
\hline \multicolumn{7}{|c|}{ Meat-based frozen meals } \\
\hline$n^{*}$ & 81 & 10,112 & 34 & 4955 & 47 & 5157 \\
\hline Mean (SE) & $959(77.3)$ & $10(1.5)$ & $1124(123.1)$ & $7(1.4)$ & $885(84.7)$ & $12(2.5)$ \\
\hline$\%$ contribution (SE) & $32(2.3)$ & $0.3(0.0)$ & $33(4.5)$ & $0.2(0.0)$ & $31(2.3)$ & $0.4(0.1)$ \\
\hline \multicolumn{7}{|l|}{ Meat-based soups } \\
\hline$n$ & 453 & 10,112 & 200 & 4955 & 253 & 5157 \\
\hline Mean (SE) & $1213(67.0)$ & $43(4.7)$ & 1328 (79.3) & $40(5.7)$ & 1129 (77.1) & $45(6.7)$ \\
\hline$\%$ contribution (SE) & $30(1.2)$ & $1.0(0.1)$ & $29(1.7)$ & $0.9(0.1)$ & $31(1.6)$ & $1.2(0.1)$ \\
\hline \multicolumn{7}{|l|}{ Meat-based gravies } \\
\hline$n$ & 255 & 10,112 & 133 & 4955 & 122 & 5157 \\
\hline Mean (SE) & 441 (41.9) & $11(1.7)$ & $533(73.2)$ & $14(3.2)$ & $335(26.1)$ & $8(0.8)$ \\
\hline$\%$ contribution $(\mathrm{SE})$ & $11(0.8)$ & $0.3(0.0)$ & $11(1.4)$ & $0.3(0.1)$ & $10(0.8)$ & $0.2(0.0)$ \\
\hline \multicolumn{7}{|c|}{ Crackers and salty snacks } \\
\hline$n$ & 1881 & 10,112 & 848 & 4955 & 1033 & 5157 \\
\hline Mean (SE) & $267(9.2)$ & $56(3.1)$ & $289(82)$ & $55(3.0)$ & $250(14.6)$ & $56(4.5)$ \\
\hline$\%$ contribution $(\mathrm{SE})$ & $8(0.3)$ & $1.7(0.1)$ & $8(0.3)$ & $1.5(0.1)$ & $8(0.4)$ & $1.9(0.1)$ \\
\hline \multicolumn{7}{|l|}{ Vegetable soups } \\
\hline n & 382 & 10,112 & 166 & 4955 & 216 & 5157 \\
\hline Mean (SE) & $1003(54.2)$ & $39(4.3)$ & $1241(108.7)$ & $39(6.2)$ & $848(58.4)$ & $39(4.9)$ \\
\hline$\%$ contribution (SE) & $27(1.3)$ & $1.0(0.1)$ & $28(1.9)$ & $0.9(0.1)$ & $26(1.7)$ & $1.2(0.1)$ \\
\hline \multicolumn{7}{|c|}{$\begin{array}{l}{ }^{1} \text { NHANES, National Health and Nutrition Examination Survey; SE, standard error. }{ }^{2} \text { The analytic sample includes } \\
\text { individuals age } \geq 19 \text { years who were not pregnant or lactating and had complete information for age and } 24 \text {-hour } \\
\text { dietary recall on day one. }{ }^{3} \text { Unlike the National Cancer Institute-adjusted statistics that represent long-term, usual } \\
\text { dietary intake estimates presented in Table 3, the food intake statistics here are estimates of intake on any given day. } \\
\text { The above sample sizes for consumers reflect a categorization of the NHANES respondents based on whether they } \\
\text { reported sodium intakes in one of the above categories, and describe the sample, not the population. Estimates } \\
\text { reflective of population intakes for the above categories are indicated by "all adults," "all men," and "all women," } \\
\text { respectively. " Estimates have SEs of concern or sample sizes of concern. }\end{array}$} \\
\hline \multirow{2}{*}{ Figure } & \multicolumn{2}{|c|}{ All Children } & \multicolumn{2}{|c|}{ Boys } & \multicolumn{2}{|c|}{ Girls } \\
\hline & Consumers & All Children & Consumers & All Boys & Consumers & All Girls \\
\hline \multicolumn{7}{|l|}{ Select cheeses } \\
\hline$n$ & 1866 & 6071 & 921 & 3077 & 945 & 2994 \\
\hline Mean (SE) & $277(7.6)$ & $94(5.0)$ & 297 (11.5) & $101(6.1)$ & $257(8.1)$ & $87(5.5)$ \\
\hline \% contribution (SE) & $9(0.2)$ & $3.2(0.1)$ & $9(0.3)$ & $3.0(0.2)$ & $10(0.3)$ & $3.3(0.2)$ \\
\hline \multicolumn{7}{|l|}{ Cured meats } \\
\hline$n$ & 1166 & 6071 & 620 & 3077 & 546 & 2994 \\
\hline Mean (SE) & $636(22.8)$ & $127(8.2)$ & $677(28.7)$ & $145(11.9)$ & $588(29.7)$ & $109(8.9)$ \\
\hline$\%$ contribution (SE) & $20(0.5)$ & $4(0.3)$ & $20(0.6)$ & $4(0.3)$ & $21(0.8)$ & $4(0.3)$ \\
\hline \multicolumn{7}{|l|}{ Meat-based frozen meals } \\
\hline$n^{*}$ & 14 & 6071 & 9 & 3077 & 5 & 2994 \\
\hline Mean (SE) & $783(56.5)$ & $2(0.7)$ & $671(61.9)$ & $3(1.0)$ & $460(45.8)$ & $1(1.1)$ \\
\hline$\%$ contribution (SE) & $31(3.9)$ & $0.08(0.02)$ & $35(5.1)$ & $0.1(0.04)$ & $25(3.3)$ & $0.05(0.04)$ \\
\hline
\end{tabular}


Table 5. Cont.

\begin{tabular}{|c|c|c|c|c|c|c|}
\hline \multirow{2}{*}{ Figure } & \multicolumn{2}{|c|}{ All Children } & \multicolumn{2}{|c|}{ Boys } & \multicolumn{2}{|c|}{ Girls } \\
\hline & Consumers & All Children & Consumers & All Boys & Consumers & All Girls \\
\hline \multicolumn{7}{|l|}{ Meat-based soups } \\
\hline$n$ & 175 & 6071 & 89 & 3077 & 86 & 2994 \\
\hline Mean (SE) & $1097(73.1)$ & $25(4.6)$ & $1168(126.1)$ & $26(5.5)$ & $1024(108.3)$ & $23(6.4)$ \\
\hline \% contribution (SE) & $36(2.1)$ & $0.8(0.2)$ & $34(2.3)$ & $0.7(0.1)$ & $38(3.5)$ & $0.9(0.2)$ \\
\hline \multicolumn{7}{|l|}{ Meat-based gravies } \\
\hline$n$ & 107 & 6071 & 62 & 3077 & 45 & 2994 \\
\hline Mean (SE) & 405 (56.6) & $10(1.7)$ & 479 (73.2) & $14(2.5)$ & $292(48.5)$ & $6(1.6)$ \\
\hline \% contribution (SE) & $10(1.4)$ & $0.2(0.04)$ & $11(1.8)$ & $0.3(0.1)$ & $9(1.4)$ & $0.2(0.05)$ \\
\hline \multicolumn{7}{|l|}{ Crackers and salty snacks } \\
\hline$n$ & 1618 & 6071 & 814 & 3077 & 804 & 2994 \\
\hline Mean (SE) & $273(15.3)$ & $75(6.0)$ & $277(15.0)$ & $75(6.5)$ & $268(23.2)$ & $75(8.0)$ \\
\hline$\circ \%$ contribution (SE) & $10(0.4)$ & $2.7(0.2)$ & $9(0.3)$ & $2.5(0.2)$ & $11(0.8)$ & $3.0(0.3)$ \\
\hline \multicolumn{7}{|l|}{ Vegetable soups } \\
\hline$n^{*}$ & 111 & 6071 & 51 & 3077 & 60 & 2994 \\
\hline Mean (SE) & 737 (92.6) & $13(2.7)$ & $812(145.2)$ & $16(4.2)$ & $639(62.5)$ & $10(2.2)$ \\
\hline$\%$ contribution (SE) & $23(2.2)$ & $0.4(0.1)$ & $21(3.3)$ & $0.4(0.1)$ & $26(1.9)$ & $0.4(0.1)$ \\
\hline
\end{tabular}

${ }^{1}$ NHANES, National Health and Nutrition Examination Survey; SE, standard error. ${ }^{2}$ The analytic sample includes individuals aged 1-18 years who were not pregnant or lactating and had complete information for age and 24-hour dietary recall on day one. ${ }^{3}$ Unlike the National Cancer Institute-adjusted statistics that represent long-term, usual dietary intake estimates presented in Table 3, the food intake statistics here are estimates of intake on any given day. The above sample sizes for consumers reflect a categorization of the NHANES respondents based on whether they reported sodium intakes in one of the above categories, and describe the sample, not the population. Estimates reflective of population intakes for the above categories are indicated by "all adults," "all men," and "all women," respectively. * Estimates have SEs of concern or sample sizes of concern.

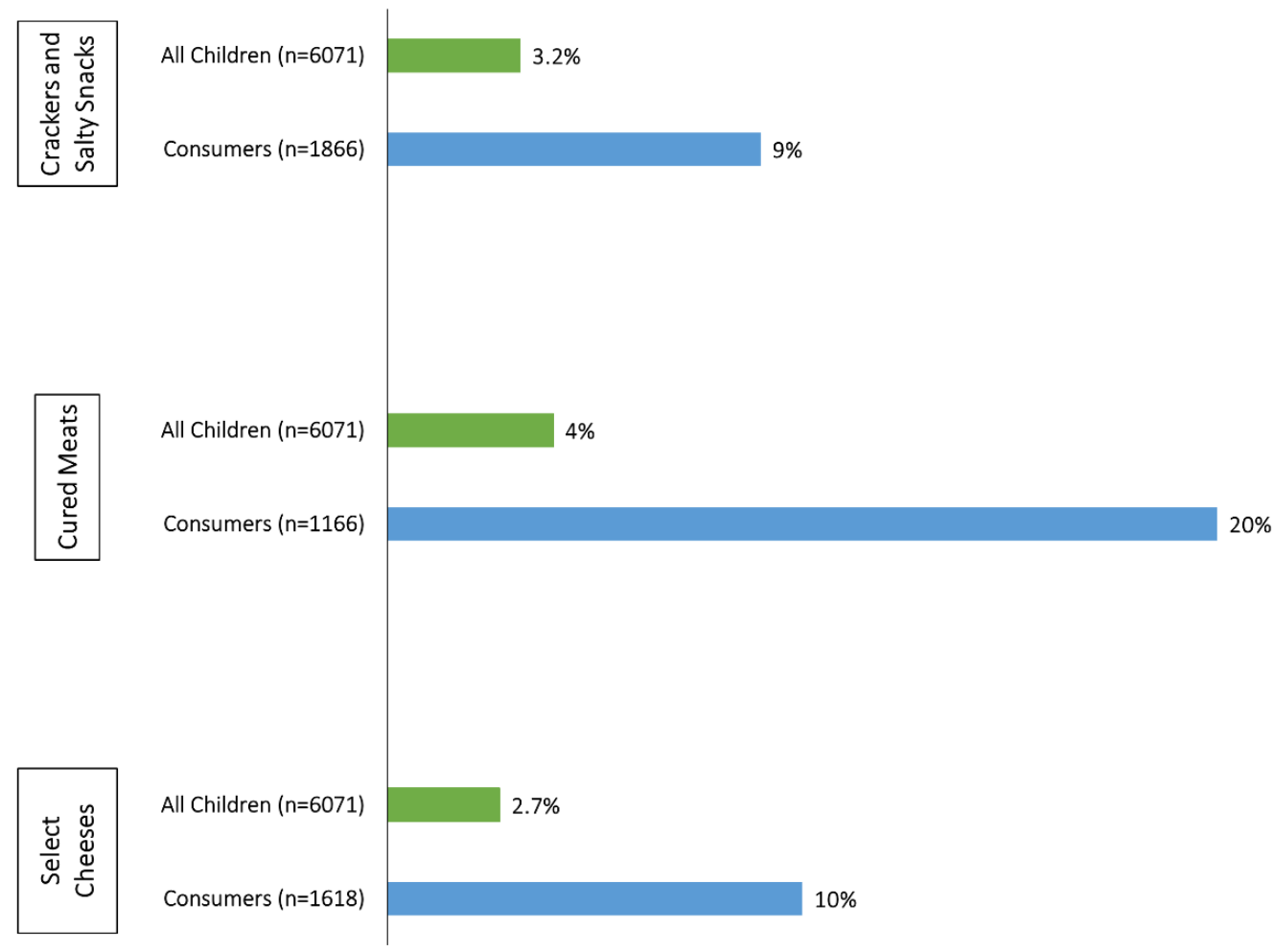

Figure 1. Percentage-wise contributions from selected food groups on total sodium intake (in milligrams) in the diets of U.S. children (aged 1-18 years), National Health and Nutrition Examination Survey 2013-2016. Based on FDA-NIH Biomarker Working Group [2] and U.S. National Academies of Sciences [1]. 
3.2. Models of the Effects of Gutamates on Mean Usual Sodium Intakes, Percentages above the CDRR, and Percentages above the UL

Universal incorporation of glutamates into the select savory food groups (presented in Table 2) would result in a 3\% (162 mg/day) reduction in overall sodium intakes in the U.S. population (aged $\geq 1$ year) and a 7-8 percentage point reduction among consumers of one or more food categories in which sodium chloride could be substituted for by glutamates. Among U.S. children specifically, glutamates have the potential to reduce the proportion of the population exceeding the UL for sodium by 5 percentage points (Table 3) and to reduce consumer intakes by $211-263 \mathrm{mg} /$ day among boys and girls. Likewise, glutamates could reduce the sodium intakes of consumers by 321 and $236 \mathrm{mg} /$ day in adult men and women, respectively (Tables 6 and 7).

Table 6. Potential sodium intake reduction with MSG in the diets of U.S. adults (aged $\geq 19$ years) who consume selected food groups by age and select food group, NHANES 2013-2016 1,2,3

\begin{tabular}{|c|c|c|c|c|c|}
\hline Figure & $n$ & $\begin{array}{l}\text { Potential } \\
\text { Reduction, } \\
\text { Mean (SE) }\end{array}$ & $\begin{array}{l}\text { Current Intake, } \\
\text { Mean (SE) }\end{array}$ & $\begin{array}{l}\text { Potential Intake } \\
\text { After Reduction, } \\
\text { Mean (SE) }\end{array}$ & Reduction (\%) \\
\hline \multicolumn{6}{|c|}{$\begin{array}{l}\text { Overall sodium (Reduction among } \\
\text { consumers of } \geq 1 \text { food groups) }\end{array}$} \\
\hline All consumers & 5639 & $278(2.7)$ & $3794(30.1)$ & $3516(27.4)$ & $7.3(0.1)$ \\
\hline Men & 2732 & $321(5.1)$ & $4407(53.0)$ & $4086(47.9)$ & $7.3(0.1)$ \\
\hline Women & 2907 & $236(1.2)$ & $3202(29.1)$ & $2966(27.9)$ & $7.4(0.0)$ \\
\hline \multicolumn{6}{|l|}{ Select cheeses } \\
\hline All consumers & 3115 & $136(3.7)$ & $303(8.2)$ & $167(4.5)$ & $45.0(0.0)$ \\
\hline Men & 1515 & $156(5.7)$ & $348(12.6)$ & $191(7.0)$ & $45.0(0.0)$ \\
\hline Women & 1600 & $116(3.9)$ & $258(8.6)$ & $142(4.7)$ & $45.0(0.0)$ \\
\hline \multicolumn{6}{|l|}{ Cured meats } \\
\hline All consumers & 1886 & $330(8.4)$ & $825(21.0)$ & $495(12.6)$ & $40.0(0.0)$ \\
\hline Men & 1049 & $363(13.5)$ & $908(33.8)$ & $545(20.3)$ & $40.0(0.0)$ \\
\hline Women & 837 & $286(9.5)$ & $715(23.6)$ & $429(14.2)$ & $40.0(0.0)$ \\
\hline \multicolumn{6}{|c|}{ Meat-based frozen meals* } \\
\hline All consumers & 81 & $240(19.3)$ & 959 (77.3) & $719(58.0)$ & $25.0(0.0)$ \\
\hline Men & 34 & $281(30.8)$ & $1124(123.1)$ & $843(92.3)$ & $25.0(0.0)$ \\
\hline Women & 47 & $221(21.2)$ & $885(84.7)$ & $663(63.5)$ & $25.0(0.0)$ \\
\hline \multicolumn{6}{|l|}{ Meat-based soups } \\
\hline All consumers & 453 & $364(20.1)$ & $1213(67.0)$ & $849(46.9)$ & $30.0(0.0)$ \\
\hline Men & 200 & $398(23.8)$ & $1328(79.3)$ & $930(55.5)$ & $30.0(0.0)$ \\
\hline Women & 253 & $339(23.1)$ & 1129 (77.1) & $790(54.0)$ & $30.0(0.0)$ \\
\hline \multicolumn{6}{|c|}{ Meat-based gravies } \\
\hline All consumers & 255 & $132(12.6)$ & $441(41.9)$ & $309(29.4)$ & $30.0(0.0)$ \\
\hline Men & 133 & $160(22.0)$ & $533(73.2)$ & $373(51.3)$ & $30.0(0.0)$ \\
\hline Women & 122 & $101(7.8)$ & $335(26.1)$ & $235(18.3)$ & $30.0(0.0)$ \\
\hline \multicolumn{6}{|c|}{ Crackers and salty snacks } \\
\hline All consumers & 1881 & $107(3.7)$ & $267(9.2)$ & $160(5.5)$ & $40.0(0.0)$ \\
\hline Men & 848 & $115(3.3)$ & $289(82)$ & $173(4.9)$ & $40.0(0.0)$ \\
\hline Women & 1033 & $100(5.8)$ & $250(14.6)$ & $150(8.8)$ & $40.0(0.0)$ \\
\hline \multicolumn{6}{|l|}{ Vegetable soups } \\
\hline All consumers & 382 & $301(16.3)$ & $1003(54.2)$ & $702(37.9)$ & $30.0(0.0)$ \\
\hline Men & 166 & $372(32.6)$ & $1241(108.7)$ & $868(76.1)$ & $30.0(0.0)$ \\
\hline Women & 216 & $254(17.5)$ & $848(58.4)$ & $593(40.9)$ & $30.0(0.0)$ \\
\hline
\end{tabular}


Table 7. Potential sodium intake reduction with MSG in the diets of U.S. children (aged 1-18 years) who consume selected food groups by age and select food group, NHANES 2013-2016 1,2,3.

\begin{tabular}{|c|c|c|c|c|c|}
\hline Food Group & $n$ & $\begin{array}{l}\text { Potential } \\
\text { Reduction, } \\
\text { Mean (SE) }\end{array}$ & $\begin{array}{l}\text { Current Intake, } \\
\text { Mean (SE) }\end{array}$ & $\begin{array}{l}\text { Potential Intake } \\
\text { After Reduction, } \\
\text { Mean (SE) }\end{array}$ & Reduction (\%) \\
\hline \multicolumn{6}{|c|}{$\begin{array}{l}\text { Overall sodium (Reduction among } \\
\text { consumers of } \geq 1 \text { food groups) }\end{array}$} \\
\hline All consumers & 3421 & $237(0.7)$ & 3047 (30.8) & $2810(30.1)$ & $7.8(0.02)$ \\
\hline Boys & 1717 & $263(1.2)$ & $3345(46.3)$ & $3082(45.1)$ & $8.5(0.02)$ \\
\hline Girls & 1704 & $211(2.9)$ & $2747(38.8)$ & $2536(35.9)$ & $7.7(0.1)$ \\
\hline \multicolumn{6}{|l|}{ Select cheeses } \\
\hline All consumers & 1866 & $125(3.4)$ & $277(7.6)$ & $153(4.2)$ & $45.0(0.0)$ \\
\hline Boys & 921 & $134(5.2)$ & 297 (11.5) & $163(6.3)$ & $45.0(0.0)$ \\
\hline Girls & 945 & $116(3.7)$ & $257(8.1)$ & $141(4.5)$ & $45.0(0.0)$ \\
\hline \multicolumn{6}{|l|}{ Cured meats } \\
\hline All consumers & 1166 & $255(9.1)$ & $636(22.8)$ & $382(13.7)$ & $40.0(0.0)$ \\
\hline Boys & 620 & $271(11.5)$ & $677(28.7)$ & $406(17.2)$ & $40.0(0.0)$ \\
\hline Girls & 546 & $235(11.9)$ & $588(29.7)$ & $353(17.8)$ & $40.0(0.0)$ \\
\hline \multicolumn{6}{|c|}{ Meat-based frozen meals } \\
\hline All consumers * & 14 & $196(14.1)$ & $783(56.5)$ & $587(42.4)$ & $25.0(0.0)$ \\
\hline Boys * & 9 & $224(20.6)$ & $895(82.5)$ & $671(61.9)$ & $25.0(0.0)$ \\
\hline Girls* & 5 & $153(15.3)$ & $613(61.0)$ & $460(45.8)$ & $25.0(0.0)$ \\
\hline \multicolumn{6}{|l|}{ Meat-based soups } \\
\hline All consumers & 175 & $329(21.9)$ & $1097(73.1)$ & $768(51.2)$ & $30.0(0.0)$ \\
\hline Boys & 89 & $350(37.8)$ & 1168 (126.1) & $818(88.3)$ & $30.0(0.0)$ \\
\hline Girls & 86 & $307(32.5)$ & $1024(108.3)$ & $717(75.8)$ & $30.0(0.0)$ \\
\hline \multicolumn{6}{|l|}{ Meat-based gravies } \\
\hline All consumers & 107 & $122(17.0)$ & $405(56.6)$ & $284(39.6)$ & $30.0(0.0)$ \\
\hline Boys & 62 & $144(22.0)$ & $479(73.2)$ & $336(51.2)$ & $30.0(0.0)$ \\
\hline Girls & 45 & $87(14.5)$ & $292(48.5)$ & $204(33.9)$ & $30.0(0.0)$ \\
\hline \multicolumn{6}{|c|}{ Crackers and salty snacks } \\
\hline All consumers & 1618 & $109(6.1)$ & $273(15.3)$ & $164(9.2)$ & $40.0(0.0)$ \\
\hline Boys & 814 & $111(6.0)$ & $277(15.0)$ & $166(9.0)$ & $40.0(0.0)$ \\
\hline Girls & 804 & $107(9.3)$ & $268(23.2)$ & $161(13.9)$ & $40.0(0.0)$ \\
\hline \multicolumn{6}{|l|}{ Vegetable soups } \\
\hline All consumers & 111 & $221(27.8)$ & $737(92.6)$ & $516(64.8)$ & $30.0(0.0)$ \\
\hline Boys * & 51 & $244(43.6)$ & $812(145.2) *$ & $569(101.7) *$ & $30.0(0.0)$ \\
\hline Girls & 60 & $192(18.7)$ & $639(62.5)$ & $447(43.7)$ & $30.0(0.0)$ \\
\hline
\end{tabular}

\section{Discussion}

Dietary factors are among the top contributors to chronic disease risk and DALYs in the United States. High intake of sodium is one risk factor that has been identified as a contributor to this burden [33]. According to our analysis, current estimates of mean usual sodium intake remain high across all age and sex subgroups of the U.S. population, and they continue to exceed authoritative recommendations, consistent with previous reports [4,6]. Contrary to prior reports [6], age-related differences in estimated usual intakes did not appear to be more pronounced in men than women (Table 3). Our analyses provide unique data on the diets of consumers of select food categories. Although reducing the amount of sodium among certain food groups may show modest effects on intakes across the population, it may have a large effect on individuals who consume these types of products. For example, about $18.7 \%$ of U.S. adults consume cured meats on any given day; reducing sodium intake of cured meat products by $40 \%$ would have a large impact on those consumers, since cured meats account for $21 \%$ of their total sodium intake from the diet. Figure 1 illustrates substantial effects of incorporating glutamates into crackers and salty snacks, cured meats, and select cheeses on U.S. children (1-18 years). Given current sources of sodium in the diets of young children, glutamate's 
use in these select categories may have the greatest impact on sodium intakes in this age group. Meat-based frozen meals, vegetable and meat-based soups, and cured meats contain the highest amounts of sodium; however, grain products were previously shown to be the largest contributor of sodium intakes to the U.S. diet because they are more ubiquitously consumed [6]. Consumer sentiment around MSG has deterred many consumer-packaged food companies from utilizing it to reduce sodium intake in products [34].

Several other strategies have been applied to reduce the population's sodium intake. Gradual reduction through a cumulative series of small decreases over 6 weeks was shown to be effective in reducing the sodium content of white bread by about $25 \%$ without altering palatability. However, reduction would need to be applied to all breads on the market to go unnoticed by consumers [35]. Potassium chloride $(\mathrm{KCl})$, calcium chloride $\left(\mathrm{CaCl}_{2}\right)$, and magnesium sulfate $\left(\mathrm{MgSO}_{4}\right)$ have been used as substitutes for table salt; however, their bitter taste has limited their use and uptake by consumers [36]. Citric acid in tomato soup [37] and lactic acid in bread [38] have the potential to enhance saltiness and be useful in reducing sodium intake. SODA-LO, a new but more costly sodium-reduction ingredient that can reduce sodium in certain applications through its technology that turns standard salt crystals into free-flowing, hollow salt microspheres, has been shown to deliver taste and function by maximizing surface area in products such as potato chips and baked goods [6].

Current intake above public health recommendations is not solely a United States-centric issue, but a global pandemic demonstrated by high intakes of sodium in other countries [39]. Assuming the accuracy of NHANES and other international databases, ongoing public health education initiatives show no signs of success in decreasing intakes. Frequent use of nutrition labels appears to be associated with lower consumption of sodium and high-sodium foods; however, while surveys suggest that consumers may wish to reduce their sodium intake, it is likely not a priority in what most consumers choose to eat [40]. In fact, evidence indicates that many consumers avoid products labeled as "low sodium" [40]. Reducing intakes through food science and technological advances seems appropriate, in order to make the most impactful reductions in the consumption of sodium at the population level.

Our study has some strengths and limitations to consider. First, the strengths of our analysis are that the models applied to examine usual intakes adjusted for the effects of within-person variation measurement error, and that NHANES is a large nationally representative sample that allows for the estimation of usual intakes of sodium at the population level. However, the limitations of our study should also be noted. This modeling study used conservative assumptions of sodium reduction by substituting glutamates for sodium chloride in several What We Eat in America food categories. We chose these conservative reduction values, presented in Table 2, upon consultation with food scientists, with the hopes of accounting for what is already contained in the food supply so as not to overestimate the total effect of glutamates. Restaurant foods supply a large portion of sodium to the U.S. diet [40]; however, we chose to not model inclusion of glutamates into restaurant foods, since many of these flavor enhancers are already in widespread use in restaurants. Therefore, the effect of glutamates could be greater than what is presented in our study. NHANES also has several limitations, including the reliance on self-reported dietary intake data and assumptions of USDA reference database accuracy for estimating sodium intakes across the population. Self-reported dietary data are prone to systematic errors, such as energy underreporting. Additionally, we cannot completely rule out the potential for self-selection bias; that is, people who participate in nutrition- and health-related research tend to differ by sociodemographic factors and may have been more interested in participating in NHANES [41]. Finally, in order to fully maximize the effectiveness of sodium reduction, the acceptability of MSG among consumers must be taken into consideration [42,43].

\section{Conclusions}

Current sodium intakes in the United States remain high and unchanged from previous NHANES cycles, exceeding public health recommendations. The addition of glutamates to certain savory food categories has the potential to help reduce the population's intake of sodium by approximately $3.0 \%$, 
and to reduce the intake by $7.3 \%$ among consumers of the product categories in which sodium chloride could be substituted for by glutamates. While reducing the amount of sodium among certain food groups may show modest effects on intakes across the adult population, it may have a large effect on those who consume those types of products.

Author Contributions: Conceptualization, T.C.W. and R.L.B.; methodology, T.C.W. and R.L.B.; formal analysis, A.E.C., with oversight from R.L.B and T.C.W.; data curation, A.E.C., with oversight from R.L.B. and T.C.W.; writing-original draft preparation, T.C.W., A.E.C., and R.L.B.; writing-review and editing, T.C.W., A.E.C., and R.L.B.; funding acquisition, T.C.W.

Funding: Funding for this manuscript was provided through an unrestricted educational grant from Ajinomoto to Think Healthy Group. The funding body had no role in the design, analysis, interpretation, or presentation of the data and results. The authors and sponsor strictly adhered to the American Society for Nutrition's guiding principles for private funding of food science and nutrition research.

Acknowledgments: The authors wish to thank Christina West for her copy-editing and formatting services.

Conflicts of Interest: T.C.W. has received scientific consulting fees from numerous food companies. All his conflicts of interest are listed at www.drtaylorwallace.com. The authors claim no other conflicts of interest to disclose.

\section{References}

1. U.S. National Academies of Sciences, Engineering, and Medicine. Dietary Reference Intakes for Sodium and Potassium; National Academies Press: Washington, DC, USA, 2019.

2. FDA-NIH Biomarker Working Group. BEST (Biomarkers, Endpoints, and Other Tools) Resource; U.S. Food and Drug Administration: Silver Spring, MD, USA, 2016.

3. Coxson, P.G.; Cook, N.R.; Joffres, M.; Hong, Y.; Orenstein, D.; Schmidt, S.M.; Bibbins-Domingo, K. Mortality benefits from US population-wide reduction in sodium consumption: Projections from 3 modeling approaches. Hypertension 2013, 61, 564-570. [CrossRef] [PubMed]

4. Bailey, R.L.; Parker, E.A.; Rhodes, D.G.; Goldman, J.D.; Clemens, J.C.; Moshfegh, A.J.; Thuppal, S.V.; Weaver, C.M. Estimating sodium and potassium intakes and their ratio in the American diet: Data from the 2011-2012 NHANES. J. Nutr. 2016, 146, 745-750. [CrossRef] [PubMed]

5. Jackson, S.L.; King, S.M.; Zhao, L.; Cogswell, M.E. Prevalence of excess sodium intake in the United States-NHANES, 2009-2012. Morb. Mortal. Wkly. Rep. 2016, 64, 1393-1397. [CrossRef]

6. Fulgoni, V.L., 3rd; Agarwal, S.; Spence, L.; Samuel, P. Sodium intake in US ethnic subgroups and potential impact of a new sodium reduction technology: NHANES dietary modeling. Nutr. J. 2014, 13, 120. [CrossRef]

7. Dunford, E.K.; Poti, J.M.; Popkin, B.M. Emerging disparities in dietary sodium intake from snacking in the US population. Nutrients 2017, 9, 610. [CrossRef]

8. Quader, Z.S.; Zhao, L.; Gillespie, C.; Cogswell, M.E.; Terry, A.L.; Moshfegh, A.; Rhodes, D. Sodium intake among persons aged $\geq 2$ years-United States, 2013-2014. Morb. Mortal. Wkly. Rep. 2017, 66, 324-338. [CrossRef]

9. Quader, Z.S.; Gillespie, C.; Sliwa, S.A.; Ahuja, J.K.; Burdg, J.P.; Moshfegh, A.; Pehrsson, P.R.; Gunn, J.P.; Mugavero, K.; Cogswell, M.E. Sodium intake among US school-aged children: National Health and Nutrition Examination Survey, 2011-2012. J. Acad. Nutr. Diet. 2017, 117, 39-47. [CrossRef]

10. Institute of Medicine. Strategies to Reduce Sodium Intake in the United States; National Academies Press: Washington, DC, USA, 2010.

11. U.S. Food and Drug Administration. Voluntary Sodium Reduction Goals: Target Mean and Upper Bound Concentrations for Sodium in Commercially Processed, Packaged, and Prepared Foods: Guidance For Industry. Available online: https:/www.fda.gov/downloads/Food/GuidanceRegulation/ GuidanceDocumentsRegulatoryInformation/UCM503798.pdf (accessed on 3 April 2019).

12. Maluly, H.D.B.; Arisseto-Bragotto, A.P.; Reyes, F.G.R. Monosodium glutamate as a tool to reduce sodium in foodstuffs: Technological and safety aspects. Food Sci. Nutr. 2017, 5, 1039-1048. [CrossRef]

13. Jinap, S.; Hajeb, P. Glutamate: Its applications in food and contribution to health. Appetite 2010, 55, 1-10. [CrossRef] [PubMed]

14. Ball, P.; Woodward, D.; Beard, T.; Shoobridge, A.; Ferrier, M. Calcium diglutamate improves taste characteristics of lower-salt soup. Eur. J. Clin. Nutr. 2002, 56, 519-523. [CrossRef] [PubMed] 
15. Yamaguchi, S.; Takahashi, C. Interactions of monosodium glutamate and sodium chloride on saltiness and palatability of a clear soup. J. Food Sci. 1984, 49, 82-85. [CrossRef]

16. Roininen, K.; Lahteenmaki, L.; Tuorila, H. Effect of umami taste on pleasantness of low-salt soups during repeated testing. Physiol. Behav. 1996, 60, 953-958. [CrossRef]

17. Jinap, S.; Hajeb, P.; Karim, R.; Norliana, S.; Yibadatihan, S.; Abdul-Kadir, R. Reduction of sodium content in spicy soups using monosodium glutamate. Food Nutr. Res. 2016, 60, 30463. [CrossRef]

18. Carter, B.E.; Monsivais, P.; Drewnowski, A. The sensory optimum of chicken broths supplemented with calcium di-glutamate: A possibility for reducing sodium while maintaining taste. Food Qual. Prefer. 2011, 22, 699-703. [CrossRef]

19. Dos Santos, B.A.; Campagnol, P.C.; Morgano, M.A.; Pollonio, M.A. Monosodium glutamate, disodium inosinate, disodium guanylate, lysine and taurine improve the sensory quality of fermented cooked sausages with $50 \%$ and $75 \%$ replacement of $\mathrm{NaCl}$ with $\mathrm{KCl}$. Meat Sci. 2014, 96, 509-513. [CrossRef] [PubMed]

20. De Quadros, D.A.; de Oliveira Rocha, I.F.; Ferreira, S.M.R.; Bolini, H.M.A. Low-sodium fish burgers: Sensory profile and drivers of liking. LWT Food Sci. Technol 2015, 63, 236-242. [CrossRef]

21. Leong, J.; Kasamatsu, C.; Ong, E.; Hoi, J.T.; Loong, M.N. A study on sensory properties of sodium reduction and replacement in Asian food using difference-from-control test. Food Sci. Nutr. 2016, 4, 469-478. [CrossRef]

22. Centers for Disease Control and Prevention. NHANES Questionnaires, Datasets, and Related Documentation. Available online: https://wwwn.cdc.gov/nchs/nhanes/Default.aspx (accessed on 17 August 2018).

23. Blanton, C.A.; Moshfegh, A.J.; Baer, D.J.; Kretsch, M.J. The USDA Automated Multiple-Pass Method accurately estimates group total energy and nutrient intake. J. Nutr. 2006, 136, 2594-2599. [CrossRef]

24. Moshfegh, A.J.; Rhodes, D.G.; Baer, D.J.; Murayi, T.; Clemens, J.C.; Rumpler, W.V.; Paul, D.R.; Sebastian, R.S.; Kuczynski, K.J.; Ingwersen, L.A.; et al. The US Department of Agriculture Automated Multiple-Pass Method reduces bias in the collection of energy intakes. Am. J. Clin. Nutr. 2008, 88, 324-332. [CrossRef]

25. Centers for Disease Control and Prevention. About the National Health and Nutrition Examination Survey. Available online: https://www.cdc.gov/nchs/nhanes/about_nhanes.htm (accessed on 17 August 2018).

26. U.S. Department of Agriculture. USDA Food Composition Databases. Available online: https://ndb.nal.usda. gov (accessed on 3 April 2019).

27. Institute of Medicine. DRI Dietary Reference Intakes: Applications in Dietary Assessment; National Academies Press: Washington, DC, USA, 2000.

28. Rodrigues, J.F.; Goncalves, C.S.; Pereira, R.C.; Carneiro, J.D.; Pinheiro, A.C. Utilization of temporal dominance of sensations and time intensity methodology for development of low-sodium Mozzarella cheese using a mixture of salts. J. Dairy Sci. 2014, 97, 4733-4744. [CrossRef]

29. Buechler, A. Consumer Acceptance Of Sodium Reduced Potato Chips And Puffed Rice. Poster Presented at Food for the Future 2019; 29 May 2019; University of Illinois, Urbana-Champaign. Available online: https://publish.illinois.edu/foodforthefuture2019/abstracts/poster-8/ (accessed on 19 July 2019).

30. National Cancer Institute. Usual Dietary Intakes: The NCI Method. Available online: https://epi.grants. cancer.gov/diet/usualintakes/method.html (accessed on 17 August 2018).

31. Rao, J.N.K.; Shao, J. Modified balanced repeated replication for complex survey data. Biometrika 1999, 86, 403-415. [CrossRef]

32. Burt, V.L.; Cohen, S.B. A comparison of methods to approximate standard errors for complex survey data. Rev. Public Data Use 1984, 12, 159-168. [PubMed]

33. Murray, C.J.; Atkinson, C.; Bhalla, K.; Birbeck, G.; Burstein, R.; Chou, D.; Dellavalle, R.; Danaei, G.; Ezzati, M.; Fahimi, A.; et al. The state of US health, 1990-2010: Burden of diseases, injuries, and risk factors. JAMA 2013, 310, 591-608. [CrossRef] [PubMed]

34. International Food Information Council. Food Decision 2016: The Impact of a Growing National Food Dialogue; International Food Information Council: Washington, DC, USA, 2016.

35. Girgis, S.; Neal, B.; Prescott, J.; Prendergast, J.; Dumbrell, S.; Turner, C.; Woodward, M. A one-quarter reduction in the salt content of bread can be made without detection. Eur. J. Clin. Nutr. 2003, 57, 616-620. [CrossRef] [PubMed]

36. Breslin, P.A.; Beauchamp, G.K. Suppression of bitterness by sodium: Variation among bitter taste stimuli. Chem. Senses 1995, 20, 609-623. [CrossRef] [PubMed]

37. Little, A.C.; Brinner, L. Taste responses to saltiness of experimentally prepared tomato juice samples. J. Am. Diet. Assoc. 1984, 84, 1022-1027. [PubMed] 
38. Hellemann, U. Perceived taste of $\mathrm{NaCl}$ and acid mixtures in water and bread. Int. J. Food Sci. Technol. 1992, 27, 201-211. [CrossRef]

39. Brown, I.J.; Tzoulaki, I.; Candeias, V.; Elliott, P. Salt intakes around the world: Implications for public health. Int. J. Epidemiol. 2009, 38, 791-813. [CrossRef]

40. Leahy, M. The sodium conundrum: Evolving recommendations and implications. Nutr. Today 2019, 54, 31-41. [CrossRef]

41. Sogaard, A.J.; Selmer, R.; Bjertness, E.; Thelle, D. The Oslo Health Study: The impact of self-selection in a large, population-based survey. Int. J. Equity Health 2004, 3, 3. [CrossRef]

42. Miyaki, T.; Retiveau-Krogmann, A.; Byrnes, E.; Takehana, S. Umami Increases Consumer Acceptability, and Perception of Sensory and Emotional Benefits without Compromising Health Benefit Perception. J. Food Sci. 2016, 81, S483-S493. [CrossRef] [PubMed]

43. Wang, S.; Adhikari, K. Consumer perceptions and other influencing factors about monosodium glutamate in the United States. J. Sens. Stud. 2018, 33, e12437. [CrossRef]

(C) 2019 by the authors. Licensee MDPI, Basel, Switzerland. This article is an open access article distributed under the terms and conditions of the Creative Commons Attribution (CC BY) license (http://creativecommons.org/licenses/by/4.0/). 